\title{
The U.S. Preventive Services Task Force: An evidence-based prevention resource for nurse practitioners
}

\author{
Tricia Trinite, MSPH, ANP, BC, (Director) ${ }^{1}$, Carol Loveland-Cherry, PhD, RN (Professor, Executive Associate \\ Dean) $^{2}$, \& Lucy Marion, PhD, RN, FAAN (Dean) ${ }^{3}$ \\ 1 Agency for Healthcare Research and Quality, Rockville, Maryland \\ 2 University of Michigan School of Nursing, Ann Arbor, Michigan \\ 3 School of Nursing, Medical College of Georgia, Augusta, Georgia
}

\section{Keywords}

Advanced practice nurse (APN); primary care; prevention, clinical practice guidelines; evidence-based practice.

\section{Correspondence \\ Tricia Trinite, MSPH, ANP, BC, Director, Prevention Dissemination \& Implementation, Center for Primary Care, Prevention and Clinical Partnerships, Agency for Healthcare Research and Quality, 540 Gaither Road, Rockville, MD 20850 \\ Tel: 301-427-1583; \\ E-mail: tricia.trinite@ahrq.hhs.gov}

Received: August 2008;

accepted: February 2009

doi:10.1111/j.1745-7599.2009.00410.x

\begin{abstract}
Purpose: To describe the work of the U.S. Preventive Services Task Force and to encourage nurse practitioners (NPs) to use its evidence-based recommendations for clinical preventive services.

Sources: Evidence reports, recommendation statements, and journal articles published under the auspices of the U.S. Preventive Services Task Force since its establishment in 1984.

Conclusions: A core competency for NPs working in primary care is knowledge about and provision of appropriate preventive services for their patients. The U.S. Preventive Services Task Force, an independent panel of experts in prevention and primary care, is an important resource for NPs.

Implications for Practice: NPs can use Task Force recommendations to guide their screening, counseling, and preventive medication decisions. They can also educate patients about the missed prevention opportunities related to underuse of effective services and the potential harms of overuse of inappropriate preventive services.
\end{abstract}

\section{Introduction}

Applying scientific principles to preventing disease and disability is basic to nursing practice. Florence Nightingale, the founder of modern nursing, established the profession on a strong scientific and prevention foundation. In the 1850s, during the Crimean War, she conducted careful analysis of environmental and outcome data and brought to light the environmental factors associated with the loss of British soldiers' lives. She followed up on her findings by advocating for improvements in sanitary conditions that yielded substantial reductions in morbidity and mortality.

Throughout her career, Nightingale emphasized that science-based nursing care puts individuals in the best position to benefit from the healing power of nature. Nurse practitioners (NPs) with advanced practice responsibilities continue the Nightingale tradition, focusing on prevention and relying on evidence to direct their practice.
The U.S. Preventive Services Task Force (USPSTF or Task Force) is an important resource for all NPs, offering them ready access to evidence-based recommendations for preventive services that will inform their primary care practice.

\section{The mandate of the U.S. Preventive Services Task Force}

The USPSTF is an independent panel of private-sector experts in prevention and primary care. First convened in 1984 by the U.S. Public Health Service, the USPSTF is currently supported by the Agency for Healthcare Research and Quality (AHRQ), which is part of the U.S. Department of Health and Human Services. The Task Force's mandate is threefold: to evaluate the benefits of particular preventive services; to make recommendations about which preventive services should be a routine part of primary medical care and for which populations; and to identify research needed as a foundation for clinical preventive care (AHRQ, 2007). 
To accomplish these tasks, the Task Force conducts rigorous, impartial assessments of the scientific evidence for a broad range of clinical preventive services, including screening, counseling, and preventive medications. The recommendations of the Task Force are intended for use in primary care delivery settings for asymptomatic patients.

Task Force members include physicians, nurses, health psychologists, and other health and methodology experts, selected through a national nomination process. Nursing has been represented on the USPSTF since its inception. Carolyn Williams, $\mathrm{PhD}, \mathrm{RN}$, led the way and was a member of the first Task Force more than 20 years ago. Other doctorate-level nurses who have been members of the USPSTF have both strong research backgrounds and expertise in prevention. Some of these nurse members have been advanced practice nurses (including Drs. Janet D. Allen, Lucy Marion, and Bernadette Melnyk), and others (Drs. Carolyn Williams, Nola J. Pender, and Carol Loveland-Cherry) have been primarily from community health nursing.

Although the intended audience for its recommendations continues to be primary care clinicians, the reach of the Task Force has expanded over time. Recommendations of the USPSTF inform recommendations developed by professional societies, coverage policies of many health plans and insurers, healthcare quality measures, and national health objectives. In fact, USPSTF recommendations are now considered the gold standard for clinical preventive services.

\section{Task Force methods}

The USPSTF currently works in conjunction with three university-based evidence-based Practice Centers (EPCs):

- The Oregon Evidence-Based Practice Center in Portland, Oregon

- The University of Ottawa Evidence-Based Practice Center in Ottawa, Ontario, Canada

- The Tufts Evidence-Based Practice Center at the Tufts Medical Center in Boston, Massachusetts

These EPCs conduct systematic reviews of the evidence for specific topics in clinical prevention. Based on these reviews and its consideration of available evidence, the USPSTF develops recommendations on a broad range of clinical preventive services, including screening, counseling, and preventive medications.

USPSTF methods have evolved to incorporate not only the quantity and quality of evidence in support of a specific preventive service but also the evidence about the harms that might result from the provision of the service. A recommendation is reached by calculating the balance between benefits and harms to produce an estimate of the net benefit of the service. Over the years, the Task Force has developed a set of explicit processes whereby it develops its recommendations and makes them public. These processes are fully described in a procedure manual and in a series of articles available on the AHRQ Web site at Www.preventiveservices.ahrq.gov (AHRQ, 2008b; Barton et al., 2007; Guirguis-Blake et al., 2007; Sawaya, Guirguis-Blake, LeFevre, Harris, \& Petitti, 2007).

The Task Force limits the topics it reviews to those conditions of public health importance that cause a large burden of suffering to society and that have the potential for substantial impact on clinical practice. Such conditions include those that are controversial and those for which there appears to be a gap between evidence and practice. The Task Force focuses its reviews on the questions and evidence most critical to making a recommendation. Each recommendation is developed based on a rigorous review of the evidence. The process whereby a recommendation is developed includes the following steps:

- Creation of an analytic framework and a set of key questions and outcomes of interest that determine the scope of the literature review.

- Systematic review of the relevant literature to answer the key questions.

- Quality rating of bodies of literature supporting each key question.

- Estimation of the magnitude of benefits and harms.

- Determination of the balance of benefits and harms of the service.

- Linking of the recommendation to the level of certainty of the evidence, and judgment about the net benefits of the service.

Each recommendation is linked to a letter grade from A (recommends the service) through D (recommends against providing the service). These grades reflect the magnitude of net benefit (balance of benefits and harms) and the strength of the evidence supporting the provision of the preventive service. When the evidence is insufficient to determine the net benefit, the Task Force issues an I statement (insufficient evidence). This can occur when evidence is lacking, of poor quality, or conflicting, so that the balance of benefits and harms cannot be determined.

Task Force recommendations are widely disseminated to professional audiences in professional journals such as Annals of Internal Medicine, Pediatrics, and Annals of Family Medicine. They are also posted on the AHRQ Web site (http://www.preventiveservice.ahrq.gov), along with the evidence reports and published articles that support each recommendation.

\section{How to use the USPSTF recommendations}

The USPSTF realizes that clinical decisions about patients involve more complex considerations than the 
evidence alone. NPs should always understand the science available but individualize decision making to the specific patient and situation to provide effective patient and family-centered care. The clinical considerations section of each USPSTF recommendation offers practical information so clinicians can tailor these recommendations to individual patients. The USPSTF suggests that clinicians in primary care practice routinely discuss and offer services with A and B recommendations with eligible patients and discourage the use of services with $\mathrm{D}$ recommendations unless there are unusual additional considerations. The Task Force also recommends against routinely providing services with a $\mathrm{C}$ grade because it is likely that the net benefit of these services is small; however, it cautions that there may be considerations that support providing the service in an individual patient.

The nature of the I statement indicating insufficient evidence to make a recommendation can be challenging to the nurse. The Task Force advises that for services with I statements, clinicians carefully read the clinical considerations section for guidance and help patients understand the uncertainty surrounding these services. Table 1 depicts the meaning and potential use of the Task Force recommendations.

\section{The potential contribution of nursing to the Task Force}

Not only can nurses use the recommendations of the Task Force in their practice, but they can also contribute strong research and practical expertise to the formulation and dissemination of these recommendations. Nurses are included among the members of the several primary healthcare professional organizations, including the American Academy of Nurse Practitioners, which serve as liaisons to the Task Force. Representatives of these partner organizations are invited to observe the USPSTF meetings, comment on evidence reviews during the recommendation development, and share in disseminating the recommendations to their constituents. Through your active involvement in these organizations, you can help promote the use of Task Force recommendations.

You can also nominate topics for the Task Force to consider. The Task Force solicits new topics for consideration through a periodic notice in the Federal Register. It also solicits suggestions directly from professional organizations, including not only the partner organizations but also other healthcare organizations.

Nursing researchers have a special contribution to make. They can add the results of their research to the Task Force knowledge base. They can find, in the Task Force recommendations, information about what research is needed to close evidence gaps that are found during the evidence reviews. They can then develop studies to help close these gaps.

\section{The underuse of preventive services: Potential nursing solutions}

Despite the continued work of the USPSTF and generation of evidence-based recommendations, many preventive services recommended ( $\mathrm{A}$ and $\mathrm{B}$ ) by the Task Force continue to be underused in primary care practice. Screening and counseling to prevent tobacco use and screening for colorectal cancer are two important examples. Nurses can play an important role in promoting the use of these services.

Tobacco may be the single most modifiable risk factor for a number of chronic illnesses (AHRQ, 2000). The Task Force strongly recommends that clinicians screen

Table 1 Task Force recommendation grades and suggestions

\begin{tabular}{|c|c|c|}
\hline Grade & Grade definitions & Suggestions for practice \\
\hline$A$ & $\begin{array}{l}\text { The USPSTF recommends the service. There is high certainty that } \\
\text { the net benefit is substantial. }\end{array}$ & Offer or provide this service. \\
\hline B & $\begin{array}{l}\text { The USPSTF recommends the service. There is high certainty that } \\
\text { the net benefit is moderate or moderate certainty that the net } \\
\text { benefit is moderate to substantial. }\end{array}$ & Offer or provide this service. \\
\hline C & $\begin{array}{l}\text { The USPSTF recommends against routinely providing the service. } \\
\text { There may be considerations that support providing the } \\
\text { service in an individual patient. There is moderate or high } \\
\text { certainty that the net benefit is small. }\end{array}$ & $\begin{array}{l}\text { Offer or provide this service only if other considerations } \\
\text { support offering or providing the service to an } \\
\text { individual patient. }\end{array}$ \\
\hline $\mathrm{D}$ & $\begin{array}{l}\text { The USPSTF recommends against the service. There is moderate } \\
\text { or high certainty that the service has no net benefit or that the } \\
\text { harms outweigh the benefits. }\end{array}$ & Discourage the use of this service. \\
\hline I Statement & $\begin{array}{l}\text { The USPSTF concludes that the current evidence is insufficient to } \\
\text { assess the balance of benefits and harms of the service. } \\
\text { Evidence is lacking, of poor quality or conflicting, and the } \\
\text { balance of benefits and harms cannot be determined. }\end{array}$ & $\begin{array}{l}\text { Read clinical considerations section of USPSTF } \\
\text { recommendation statement. If offered, patients should } \\
\text { understand the uncertainty about the balance of } \\
\text { benefits and harms. }\end{array}$ \\
\hline
\end{tabular}


all adults for tobacco use and provide tobacco cessation interventions for those who use tobacco products (AHRQ, 2003). Although it is known that the greater the intensity of the intervention combined with follow-up, the more likely the patient is to stay smoke-free, the Task Force has also found that just 3-5 minutes of counseling and medication advice given to adult smokers by their primary care clinician is effective. Because there are more than 435,000 tobacco-related deaths each year from heart disease, stroke, lung cancer, and chronic lung disease among U.S. adults, the effect of this simple intervention, combined with other effective modes of tobacco treatment, would be dramatic. Unfortunately, the 2007 National Healthcare Quality Report found that only about $60 \%$ of patients who smoke receive such advice during a routine office visit (AHRQ, 2008a). The recently published U.S. Public Health Service guideline, Treating Tobacco Use and Dependence: 2008 Update, suggests ways of improving this situation (USDHHS/PHS, 2008).

Screening for colorectal cancer is another underused A rated service that nurses can promote. The Task Force recommends that clinicians screen men and women 50 years of age or older for colorectal cancer (USPSTF, 2008 b). Colorectal cancer is our nation's second leading cause of cancer mortality and one of the most preventable cancers. If adenomatous polyps are removed before they become cancer, lives are saved. Yet only about half of adults over the age of 50 receive appropriate colorectal cancer screening with fetal occult blood testing, flexible sigmoidoscopy, colonoscopy, or double-contrast barium enema (AHRQ, 2006).

\section{Counteracting overuse of preventive services}

Although our present healthcare system does not maximize the opportunity to prevent disease or detect it early, there is also a problem with overuse of inappropriate services, which increases healthcare costs, decreases the focus on effective services, and potentially harms patients. Merenstein, Daumit, and Powe (2006) found that overuse of several preventive services not recommended, receiving a $\mathrm{D}$ recommendation by the USPSTF, costs \$47-\$194 million in annual direct medical costs. These services include overuse of routine urinalysis and electrocardiograms (EKGs). Potential reasons for overuse of nonrecommended services include clinicians responding to patient expectations for testing, being unaware of the evidence against the routine use of a screening, and ordering screening tests just in case, in a defensive manner. Less use of D recommended services can decrease the waste in our health care system in addition to avoiding potential harms caused by further diagnostic tests. Nurses can help make this happen by educating themselves and their patients about preventive services that are not needed because they have shown no net benefit or the harms outweigh the benefits.

\section{Nursing and the effort to cross the quality chasm}

The Institute of Medicine (IOM) documented disturbing shortfalls in the quality of health care in the United States, including the quality of preventive care services. In its 2001 report, Crossing the Quality Chasm: A New Health System for the 21 st Century, the IOM focused national attention on system changes needed to decrease the sizable gap, or chasm, between what we know from evidence and what we do in clinical practice. As described above, quality-ofcare indicators document very well the gaps between recommended preventive services and what is actually done in clinical practice. These gaps illustrate that the availability of sound, evidence-based recommendations for appropriate clinical preventive services is insufficient to ensure that clinicians routinely offer, and patients receive, these services. NPs and other members of a primary care team face barriers to delivering appropriate preventive services.

These barriers can be viewed on three levels: the system level, the clinical provider level, and the patient level. System barriers include clinical delivery systems organized better to respond to acute care needs than to proactively address prevention, the underuse of multidisciplinary teams to include health promotion specialists or the lack of standing orders for nurses to deliver routine immunizations and screening, and the inadequate use of health information technology. Nurse-practitioner-level barriers include competing demands in primary care settings; the lack of time and resources, which is hampered by inadequate reimbursement for counseling services; and the lack of clinical decision support tools and automatic reminders that could help ensure patients are receiving the right care at the right time.

Patient barriers are substantial and can include lack of knowledge regarding what preventive services are appropriate for themselves and family, lack of access to health care, lack of community and family support for healthy living habits, and inadequate health literacy that interferes with shared decision making with their NP. All these areas are potential foci for research.

\section{Resources available to help close the quality gap}

AHRQ offers a series of tools to facilitate the use of Task Force recommendations. The AHRQ-supported Put Prevention into Practice program, created almost 20 years ago shortly after the first USPSTF was convened, 
translates the recommendations into easy-to-use abridged publications, electronic tools, and consumer materials.

In 2005, AHRQ responded to requests from primary care clinicians to make the USPSTF recommendations accessible in a simple and easy-to-use format, and released the first abridged pocket-sized publication of current Task Force recommendations, The Guide to Clinical Preventive Services 2005 (USPSTF, 2008a).

This annually updated guide is being used by nurses, physicians, and others as a tool to provide decision support at the point of patient care, making it easier for clinicians to consult the recommendations and clinical considerations in their daily practice. In addition, the guide is being integrated into nursing curricula for NP students.

The guide includes the Task Force's recommendations on prevention and early detection for cancer; heart and vascular diseases; infectious diseases; injury and violence; mental health conditions and substance abuse; metabolic, nutritional, and endocrine conditions; musculoskeletal conditions; and obstetric and gynecological conditions. Recommendations are presented in an indexed, easyto-use format, with at-a-glance charts. The guide was focus-tested with NPs, physicians and physician assistants to best meet the needs of busy clinicians. The Guide to Clinical Preventive Services 2008 is now available.

The Electronic Preventive Services Selector (ePSS) is an electronic tool designed to help primary care clinicians identify the screening, counseling, and preventive medication services that are appropriate for their patients. The ePSS is available as a PDA application and as a web-based tool. The ePSS helps clinicians search the current Task Force recommendations by individual patient characteristics such as age, sex, and selected behavioral risk factors.

AHRQ has also developed printed materials you can use to inform your patients and prompt them to request appropriate preventive services and track their results: of particular note is a new pair of checklists, for men and for women over age 50, listing daily steps to good health as well as appropriate preventive medicines and screening tests. All of these resources are available electronically at www.preventiveservices.ahrq.gov.

Receiving reimbursement for providing preventive services is especially important and can be facilitated with better understanding of the applicable CPT codes (Current Procedural Terminology Codes) used to bill healthcare services. AHRQ partnered with the National Business Group on Health and the Centers for Disease Control and Prevention (CDC) to develop A Purchaser's Guide to Clinical Preventive Service: Moving Science into Coverage. This tool was developed to make it easy for employers and other health care purchasers to develop an evidence-based benefits design for preventive services. The purchaser's guide includes CPT codes for the A and B recommendations of the USPSTF. This resource can be found at http://www.businessgrouphealth.org/benefitstopics/ topics/purchasers/index.cfm.

\section{The challenge of supporting healthy behaviors}

The Task Force's counseling recommendations pose a special challenge to NPs who want to implement them routinely in their practice. NPs understand the importance of primary prevention and desire to support their patients' efforts to change unhealthy behaviors such as tobacco use, unhealthy dietary habits, and lack of physical activity.

A common model used to guide behavioral counseling is the 5As model, which involves five steps: (1) assess health behavior; (2) advise briefly about health risks and benefits of change; (3) agree on collaboratively set goals; (4) assist to identify and overcome barriers; and (5) arrange for follow-up. Although this model offers a framework that is evidence-based and moves nurses beyond health education alone, health behavior change is difficult and failed efforts to help patients can be frustrating to clinicians (Whitlock, Orleans, Pender, \& Allen, 2002).

The effectiveness of clinicians in promoting healthy behaviors is maximized when using multifaceted interventions instead of selecting a subset of the steps in the 5A model (Glascow, Goldstein, Ockene, \& Pronk, 2004; Woolf et al., 2005). However, robust implementation of all 5As in a primary care practice, with competing demands and reimbursement constraints that do not cover comprehensive counseling services, is difficult. In addition, patients may have better access to and prefer to receive some of these services in their home, through telephonic support services, or in their local community through community-based and public health interventions outside of the clinic walls. Developing relationships and referral linkages between local clinical practices and public health programs to promote healthy behaviors can maximize limited resources and help bridge a historical split between clinical healthcare services and public health interventions.

Tobacco cessation programs offer examples that demonstrate how clinical and community strategies can be linked, potentially increasing the use and effectiveness of these strategies. Approaches for linking clinical and community services include such things as computer linked systems, where referrals are automatically made from a clinician to a community-based program and vice versa, or a fax referral system that links patients seen in clinics with telephonic tobacco quitlines with information fed back to the clinical referral source (Ockene et al., 2007; Woolf et al., 2005). These new approaches have been tested in practice-based research networks. For more 
information, see the AHRQ Innovations Exchange at http://www.innovations.ahrq.gov/learn_network/ esources-for-linking.aspx.

\section{The role of the Task Force on Community Preventive Services}

Preventing chronic illnesses and disability will require a multipronged effort for success and includes the delivery of both evidence-based clinical preventive services and public health interventions. Just as the AHRQ-supported USPSTF makes recommendations for preventive services for primary care clinicians, the CDC-supported Task Force on Community Preventive Services (CTF) makes evidence-based recommendations for interventions that promote population health and public health. The CTF recommendations can be found at http://www.thecommunityguide.org. The CTF can be searched for information about public health programs to promote healthy behaviors. Building referral linkages and partnerships between the primary care clinics and public health or community-based organizations will build a patient-centered approach by supporting health behavior change during a clinical visit and extending support beyond the clinic walls to locations where patients live, work, play, and go to school.

In summary, NPs have key leadership roles in both clinical and public health settings and should be aware and make maximum use of the evidencebased recommendations from both of these unbiased, independent task forces.

\section{References}

Agency for Healthcare Research and Quality. (2000). Treating Tobacco Use and Dependence-A Systems Approach. A Guide for Health Care Administrators, Insurers, Managed Care Organizations, and Purchasers. Retrieved May 1, 2008 , from http://www.ahrq.gov/clinic/tobacco/systems.htm

Agency for Healthcare Research and Quality. (2003). Counseling to Prevent Tobacco Use. U.S. Preventive Services Task Force Recommendation Statement. Retrieved August 8, 2008, from http://www.ahrq.gov/clinic/uspstf/uspstbac.htm

Agency for Healthcare Research and Quality. (2006). 2006 National Healthcare Quality Report. AHRQ Publication No. 07-0013. Retrieved May 1, 2008, from http://www.ahrq.gov/qual/nhqr06/report/Chap2.htm\#cancer

Agency for Healthcare Research and Quality. (2007). About USPSTF: The New U.S. Preventive Services Task Force. Updated November 2007. Retrieved May 1, 2008, form http://www.ahrq.gov/clinic/uspstfab.htm

Agency for Healthcare Research and Quality. (2008a). 2007 National Healthcare Quality Report. AHRQ Publication No. 08-0040. Retrieved May 1, 2008, from http://www.ahrq.gov/qual/qrdr07.htm

Agency for Healthcare Research and Quality. (2008b). U.S. Preventive Services Task Force Procedure Manual. AHRQ Publication No. 08-05118-EF. Retrieved August 7, 2008, from http://www.ahrq.gov/clinic/uspstf08/methods/procmanual.htm

Barton, M. B., Miller, T., Wolff, T., Petitti, D., LeFevre, M., Sawaya, G, et al. (2007). U.S. Preventive Services Task Force. How to read the new recommendation statement: Methods update from the U.S. Preventive Services Task Force. Annals of Internal Medicine,, 147(2), 123-127.
Glascow, R. E., Goldstein, M. G., Ockene J. K., \& Pronk N. P. (2004). Translating what we have learned into practice: Principles and hypotheses for interventions addressing multiple behaviors in primary care. American Journal of Preventive Medicine, 27, 88-101.

Guirguis-Blake, J., Calonge, N., Miller, T., Siu, A., Teutsch, S., \& Whitlock E. (2007). Current processes of the U.S. Preventive Services Task Force: Refining evidence-based recommendation development. Annals of Internal Medicine, 147, 117-22. Retrieved May 1, 2008, from http://www.ahrq.gov/clinic/uspstf07/methods/currprocess.htm Institute of Medicine, Committee on Quality of Health Care in America. (2001). Crossing the quality chasm: A new health system for the 21st century. Washington, DC: National Academies Press.

Merenstein, D., Daumit G. L., \& Powe N. R. (2006). Use and costs of nonrecommended tests during routine preventive health exams. American Journal of Preventive Medicine,, 30(6), 521-527.

Ockene J. K., Edgerton, E. A., Teutsch, S. M., Marion, L. N, Miller, T., Genevro J. L, et al. (2007). Integrating evidence-based clinical and community strategies to improve health. American Journal of Preventive Medicine, 32, 244-252.

Sawaya, G. F., Guirguis-Blake, J., LeFevre, M., Harris, R., \& Petitti, D. (2007). Update on the methods of the U.S. Preventive Services Task Force: Estimating certainty and magnitude of net benefit. Annals of Internal Medicine, 147(12), 871-875. Retrieved May 1, 2008, from

http://www.ahrq.gov/clinic/uspstf07/methods/benefit.htm

U.S. Department of Health and Human Services, Public Health Service. (2008). Clinical Practice Guideline. Treating Tobacco Use and Dependence: 2008 Update. Retrieved July 22, 2008, from http://www.surgeongeneral.gov/tobacco/treating_tobacco_use08.pdf U.S. Preventive Services Task Force. (2008a). Guide to Clinical Preventive Services, 2008. AHRQ Publication No. 08-05122. Retrieved October 16, 2008, from http://www.ahrq.gov/clinic/pocketgd.htm

U.S. Preventive Services Task Force. (2008b). Screening for colorectal cancer: U.S. Preventive Services Task Force Recommendation Statement. Annals of Internal Medicine, 149(9), 627-637. Retrieved October 7, 2008, from www.annals.org and http://www.ahrq.gov/clinic/uspstf/uspscolo.htm Whitlock E. P., Orleans C. T., Pender N., \& Allan J.. (2002). Evaluating primary care behavioral counseling interventions: An evidence-based approach. American Journal of Preventive Medicine,, 22(4), 267-284.

Woolf, S. H., Glascow, E. E., Krist, A., Bartz, C., Flocke, S. A., Holtrop, J. S, et al. (2005). Putting it together: Finding success in behavior change through integration of services. Annals of Family Medicine, 3(Supplement 2), S20-S27.

\section{Statement regarding copyright}

This article was prepared at the Federal Agency for Healthcare Research and Quality (AHRQ) and is in the public domain. The content may be used without permission.

\section{Disclaimer}

The findings and conclusions in this article are those of the authors, who are responsible for its content, and do not necessarily represent the views of AHRQ. No statement in this report should be construed as an official position of AHRQ or of the U.S. Department of Health and Human Services.

The information in this article is intended to help clinicians, employers, policymakers, and others make informed decisions about the provision of healthcare services. This article is intended as a reference and not as a substitute for clinical judgment. 